\title{
High performing building as a pier for sustainable tourism in the protected area of Bracciano Lake in Italy
}

\author{
F. Cumo ${ }^{1}$, F. Cinquepalmi ${ }^{2}$, E. Pennacchia ${ }^{1} \&$ V. Sforzini ${ }^{1}$ \\ ${ }^{I}$ CITERA, Sapienza University of Rome, Italy \\ ${ }^{2}$ MIUR. Italian Ministry for Instruction and University, Italy
}

\begin{abstract}
This work deals with the design of an energy highly performing wooden building on the lake shore, inside the protected area of Bracciano-Martignano (Italy, neighbourhood of Rome).

It is a structure housing a bar, a box office and a small pier for a mini-cruise service, with the view of promoting sustainable tourism in the Trevignano area.

Up to now, according to local legislation, only electrically powered navigation is allowed in Bracciano Lake: the mini-cruise service, utilizing a boat used no longer by the coast guard and carrying 20 people at most, will be equipped with an electrical device of $8.6 \mathrm{kWp}$ integrated with the roof of the building.

The architecture and plant designs of the wooden building are based on new envelope technologies solutions with a large use of local natural materials and pre-fabricated systems.

According to Italian regulations on building energy classification, the designed building is classified "A+", the best efficiency class, due to a high performing wooden envelope system associated with remarkable production of electrical and thermal solar energy.

The green building certification system, the so called "Protocollo Itaca", shows that the structure design (classified in the second best category) is an important pattern of eco-architecture and of strategy against the loss of biodiversity.
\end{abstract}




\section{Introduction}

The protected natural areas are zones where it is necessary to protect, promote, improve and preserve the patrimony of the biological, cultural and natural diversities in which the Italian countryside is so rich as to be considered unique in the world.

In fact in Italy the protected natural areas are 772 ; they cover $11 \%$ of the whole country and involve $17.000,000$ resident citizens.

These areas differentiate not only for their different natural environments and historical/cultural inheritance but also for the different administrative, restrictive and preservative regulations they are subject to.

Nowadays they are sort of laboratories where new forms of sustainable development can be tested and promoted [1].

Moreover, for the last fifteen years also the aim of promoting the economic and social development of the local communities has been pursued: natural spaces of great value offer many opportunities to carry out projects capable of establishing a correct mutual relationship between nature and its users as regards tourism; the Italian protected natural areas can supply a large offer of didactic, recreational and sport activities in harmony with the environment requirements, which favours an immediate deep feeling for the natural world and a greater attention to the problems of its protection and sustainability.

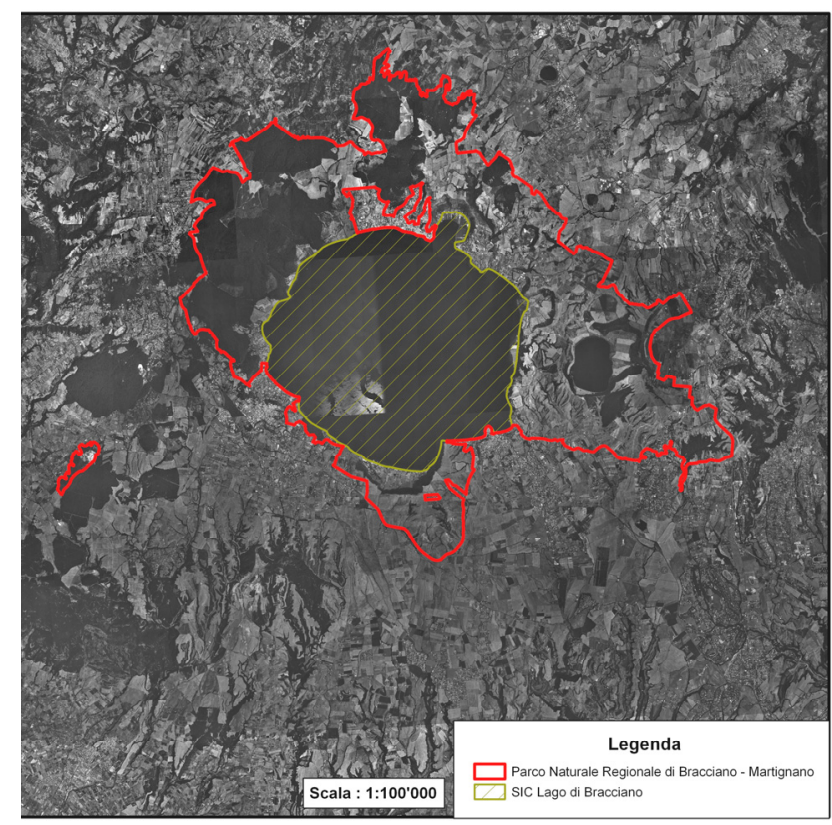

Figure 1: $\quad$ Bracciano-Martignano Park protected area. 
The natural park of Bracciano-Martignano was constituted on November 25, 1999 in order to promote the preservation and development of the area and of the natural/cultural resources of the wide district of the Sabatini Mountains. It extends between the provinces of Rome and Viterbo and includes Bracciano Lake and Martignano Lake, which occupy, with a surface of 6.000 hectares, about $1 / 3$ of the park extent of 16.682 hectares.

The forest covers about $30 \%$ of the whole protected area with wide chestnut grows, oak plantations and beech-wood.

The plenty of natural surroundings favours the presence of several kinds of animals: from the big mammalia to the 30 species of birds.

The present work shows a possible strategy for the implementation of tourism and for the fruition of this wide protected area.

\section{Technologies for a sustainable building}

Trevignano Romano is a municipality of about 6.000 inhabitants situated along the western side of Bracciano Lake, at the southern foot of the Sabatini Mountains.

The lake is almost circular with a diameter of $9 \mathrm{Km}$ and a maximum depth of $174 \mathrm{~m}$; it is a sort of catch basin for the city of Rome, in case of water emergency. The town is part of the " $\mathrm{D}$ " climatic zone; its clime is temperate thanks to the lake which mitigates the changes of temperature.

Trevignano Romano [2] is included in the natural park of BraccianoMartignano and, consequently, is subject to several rules for the protection of the landscape.

The design consists of a light structure made of eco-compatible materials such as local chestnut wood; dry stratification technology has been used, in order to offer high safety standards, short construction times, versatility and ecosustainability.

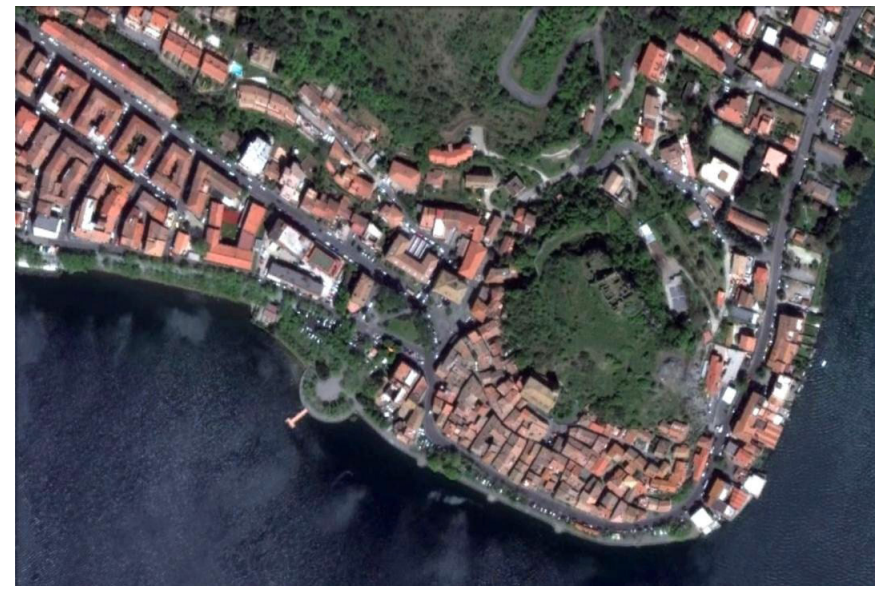

Figure 2: $\quad$ Particular of the area near the pier in Trevignano Romano. 
The building is based on the principle of pre-fabrication and removability [3]; as regards to energy, it is self-feeding due to the presence of photovoltaic panels integrated with its roof and thermal solar collectors for the production of hot sanitary water. In addition, a plant for the recovery of rain water is considered.

The kiosk occupies a surface of about $60 \mathrm{~m}^{2}$ and is $3 \mathrm{~m}$ high, on the average.

In the northern side there are sanitary service and storage and a technical room where the batteries of the photovoltaic plant are housed and the batteries of the electrically powered touristic boat are recharged.

A bar and a ticket office are situated in the southern side, together with a box office and a small pier for a mini-cruise service, in a view of promoting a sustainable tourism in Trevignano area.

Up to now, according to the local legislation, only electrically powered navigation is allowed in Bracciano Lake: the mini-cruise service, utilizing a boat, used no longer by coast guard and carrying 20 people at most, will be equipped with an electrical engine integrated with the roof of the building.

The kiosk is partly dismountable and, in fact bar ticket office and storage are to be dismantled in winter, while the photovoltaic platform and the public baths are permanent structures and in winter time the photovoltaic plant feeds, free of charges, the lighting system of the promenade. Consequently, two types of wall have been used.

1. Dismountable: an insulator and OSB (Oriented Strande Board).

2. Permanent: a insulator and XLam (Cross Laminated Timber Panels).

The transmittances of both structures are less than the lowest transmittances required by law requirements.

The structure rests on a pile of chestnut wood, which is less subject than other kinds of wood to the climate change and, in particular, to the action of fresh water.

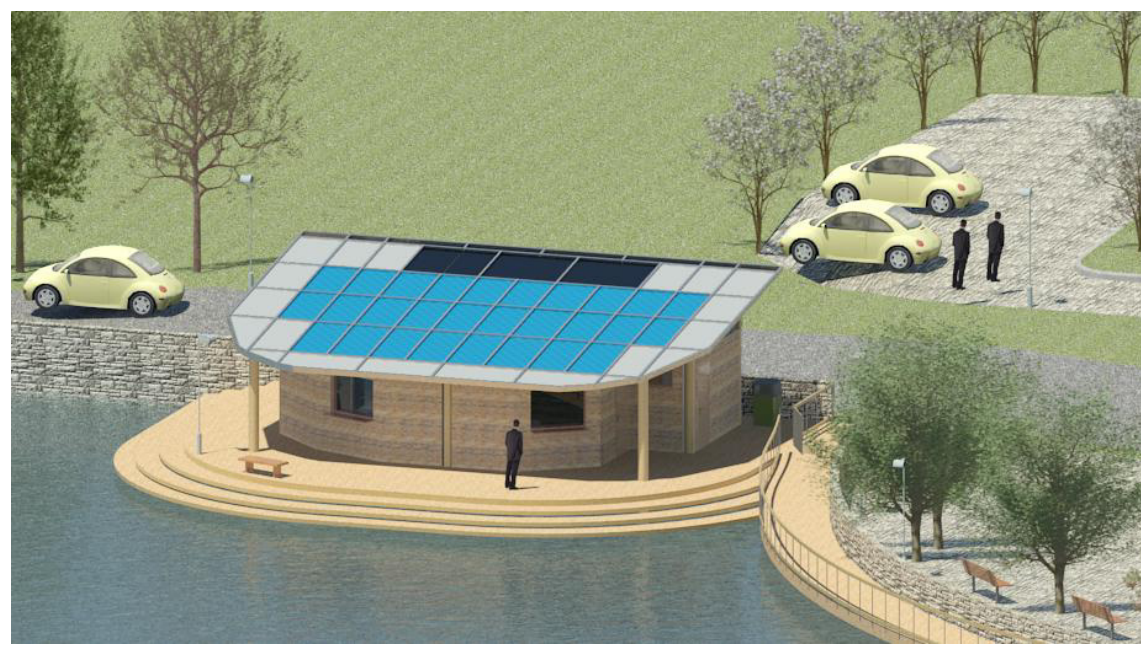

Figure 3: Overall view of the Pier. 


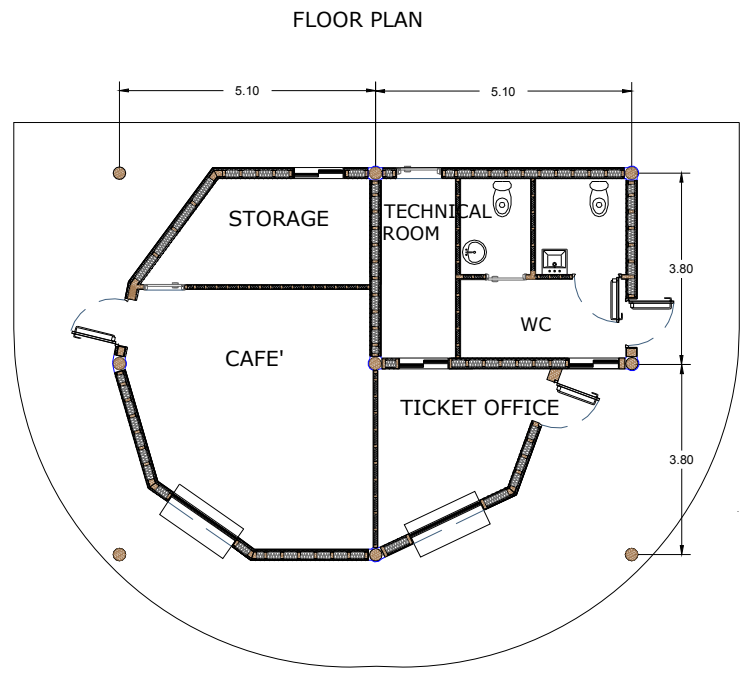

Figure 4: $\quad$ Floor level plant.

ROOF PLAN

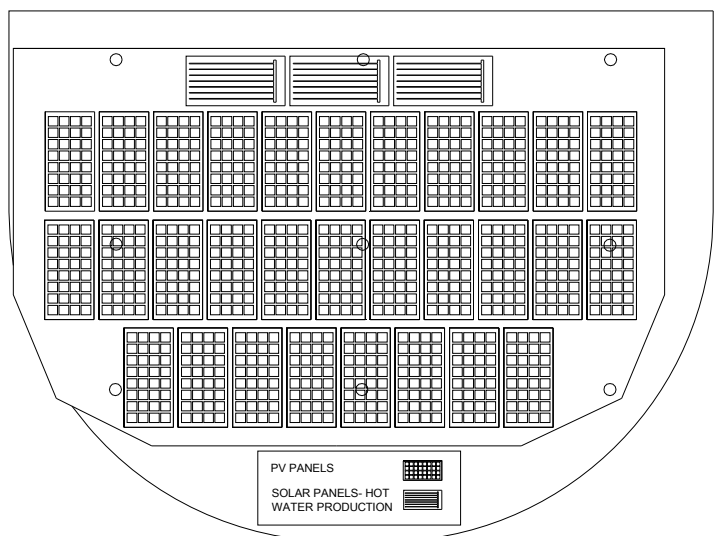

Figure 5: Roof level plant. 


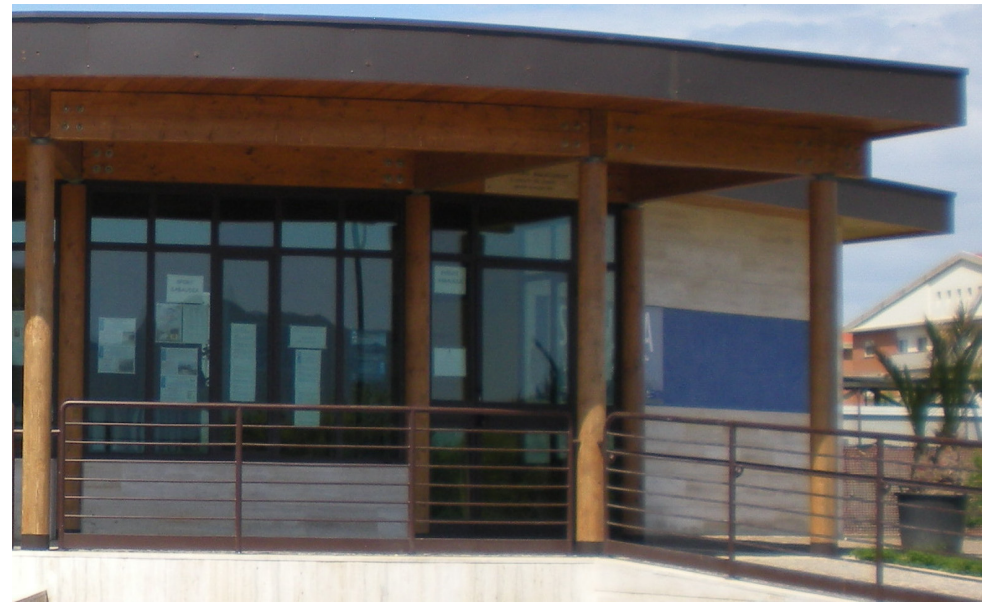

Figure 6: Particular of the wooden-glass structure.

\section{Environmental energy classification}

According to the Italian regulation on the building energy classification, the designed building is classified "A+", the best efficiency class, thanks to the highly performing wooden envelope system together with a considerable production of electrical and thermal solar energy.

In fact a photovoltaic power plant of $8.6 \mathrm{Kwp}$ is integrated with the roof of the building supplying energy for the recharging of the batteries of the boat electrical engine and for the internal loads of the bar and of the box office.

Solar panels cover the hot water consumption of the whole building $(720 \mathrm{~L} / \mathrm{d})$ from March to October.

The green building certification system, the so called "Protocollo Itaca", shows that this structure, classified in the second best category, is an important example of the best design practise in the fields of eco-architecture and of the strategy against the loos of biodiversity $[4,5]$.

The results are due to:

- a large use of natural, local and recycled materials (in our case, no materials have been recycled being the structure in question a new one)

- a large use of pre-fabricated systems in order to shorten the construction times and to reduce the building yard area

- the design of a rain-water recovering system able to store and reuse 97.200 L/y

- a significant reduction $(9.000 \mathrm{Kg} / \mathrm{y})$ of $\mathrm{CO}_{2}$ emissions through the use of technological installations

For a better comprehension of the Italian new green building certification the following table shows certification criteria and weights of the "Protocollo Itaca". 


\begin{tabular}{|c|}
\hline ITACA PROTOCOL CERTIFICATION CRITERIA \\
\hline 1. SITE QUALITY \\
\hline 1.2 SERVICE FACILITIES \\
\hline 1.2.1 PUBLIC TRANSPORT ACCESSIBILITY \\
\hline 2. RESOURCE CONSUMPTION \\
\hline 2.1 NON RENEWABLE ENERGY \\
\hline 2.1.4 HEATING ENERGY CONSUMPTION \\
\hline 2.1.8 COOLING ENERGY CONSUMPTION \\
\hline 2.1.9 DOMESTIC HOT WATER CONSUMPTION \\
\hline 2.2 RENEWABLE ENERGY \\
\hline 2.2.2 ELECTRIC POWER FROM RENEWABLE ENERGY \\
\hline 2.3 ECO-FRIENDLY MATERIALS \\
\hline 2.3.1 RENEWABLE MATERIALS \\
\hline 2.3.2 BUILDING RIUSED/RECYCLED MATERIALS \\
\hline 2.3.3 REGIONAL MATERIALS \\
\hline 2.4 WATER CONSUMPTION \\
\hline 2.4.1 WATER RECOVERY FOR IRRIGATION \\
\hline 2.4.1 DRINKING WATER FOR INDOOR USE \\
\hline 3. ENVIRONMENTAL LOADS \\
\hline $3.1 \mathrm{CO}_{2}$ EMISSIONS \\
\hline 3.1.2 WORKING FACE EMISSION \\
\hline 4 INDOOR ENVIRONMENTAL QUALITY \\
\hline 4.1 VENTILATION \\
\hline 4.1.1 NATURAL VENTILATION \\
\hline 4.3 VISUAL COMFORT \\
\hline 4.3.1 DAY LIGHTING \\
\hline 4.4 ACOUSTIC COMFORT \\
\hline 4.4.1 BUILDING ENVELOPE ACOUSTIC INSULATION \\
\hline 5.SERVICE QUALITY \\
\hline 5.1 SYSTEM CONTROLS \\
\hline $\begin{array}{l}\text { 5.1.1 BACS (Building Automation and Control System) and TBM } \\
\text { (Technical Building Management) }\end{array}$ \\
\hline
\end{tabular}

Figure 7: $\quad$ ITACA protocol certificate general criteria. 
The thermal consumption of the Pier is about $18 \mathrm{~kW} / \mathrm{hm}^{2} \mathrm{y}$ including hot water for baths consumption feed by solar panels. The entire thermal load is provided by a high efficiency heat pump consisting in a trial split system integrated with a total heat exchanger ( $70 \%$ of efficiency) for indoor air quality working with a flow rate of $1000 \mathrm{~m}^{3} / \mathrm{h}$.

Indoor and outdoor lightning is based on high efficiency led system and all internal electrical devices, including refrigerators, are supplied by a $24 \mathrm{~V}$ line DC coming directly from the photovoltaic system able to produce about $9500 \mathrm{kWh} / \mathrm{y}$.

The result has been an architecture designed for the touristic enjoinment of the lake. The score obtained (medium/high level) has been the highest obtainable in the case of a structure newly built in urban ambit in a temperate zone.

In fact, to obtain higher scores it would have been necessary to have reused materials available in situ and moreover, to maximize the score concerning the production of energy from renewable sources, it would be absolutely necessary, to make use of a micro-eolic production system; such a plant is ill-suited to our site where the prevalent winds are too changeable and too feeble.

\section{Conclusion}

Prefabrication building techniques together with the exploitation of local materials - the chestnut wood is available in great quantity in the central Apennine area - enabled us to design a highly ecocompatible structure, as verified through a dedicated analysis (LCA) and certified by the Itaca Protocol (environmental certification protocol).

The realization and utilization of the structure fully comply with the activities stated in the Sustainable Energy Action Plan (SEAP) and with the EU strategies illustrated in the "Europe 2020" document. Those strategies show that, from now for an intelligent, sustainable, "inclusive" growth, it is necessary to recourse to the most innovative sustainable building technologies in order to reach the EU goals of increasing the use of renewable energy sources and promoting energy efficiency. Such goals, with regard to the environment, will at the same time realize the preservation of local biodiversity and the whole fruition of touristic attraction.

\section{References}

[1] Cinquepalmi F., Gugliermetti, F, Cumo, F., Technologies for sustainable building the pilot project of the municipality of Rome, Palombi and partner 2008

[2] www. comune.trevignanoromano.it

[3] Berta L., Bovati M., Wood Design - Maggioli editore 2007.

[4] De Santoli L., Moncada G., Fondamenti di sostenibilità energeticoambientale, 2008.

[5] www.itaca.org/valutazione_sostenibilita.asp 